\title{
Air Quality and Human Health among a Low Income Community in the Highveld Priority Area
}

\author{
Caradee Y Wright ${ }^{1}$, Riëtha Oosthuizen, Juanette John, Rebecca M Garland, Patricia Albers and Christiaan Pauw * \\ CSIR Environmental Health Research Group, Pretoria, South Africa. \\ NOVA Institute, Pretoria, South Africa \\ ${ }^{1}$ CSIR PO Box 395, Pretoria, 0001; Email cwright@csir.co.za; Tel: +27 12841 3092; Fax: +27 128414257
}

\begin{abstract}
Human exposure to poor air quality is linked to adverse health effects. The largest burden of air pollution-related diseases is in developing countries where air pollution levels are also among the highest in the world. In South Africa, two geographic areas, the Vaal Triangle and the Highveld, have been identified for air quality management interventions to ensure compliance with National Air Quality Management Standards and to control potential harmful air pollution impacts on human health. The Highveld Priority Area (HPA) is characterised by intense mining, coal-fired power plants, industries, including iron and steel manufacturing, chemical plants, agricultural activity, motor vehicles and domestic fuel burning. Apart from two previous studies, no respiratory health studies have been carried out in the HPA. This paper describes the results of a recent, comprehensive study of ambient air quality, potential exposure to air pollution and air-related human health among a low income community living in the HPA in order to better understand the impact of air pollution on human health in South Africa.
\end{abstract}

Key words: Air quality, respiratory health, Highveld Priority Area.

\section{Introduction}

Human exposure to poor air quality is linked to adverse health effects, ranging from acute symptoms, such as nose and throat irritation, to chronic and debilitating illness and disease. The World Health Organization (WHO) states that chronic respiratory diseases, (i.e. asthma, chronic obstructive pulmonary disorder, and pneumonia), are among the leading causes of mortality and morbidity (WHO, 2007; WHO, 2010), and while not all of these adverse health effects are caused by air pollution, they are all exacerbated by the presence of poor air quality. Empirical evidence suggests that the largest burden of air pollution-related diseases is in developing countries where air pollution levels are also among the highest in the world (Krzyzanowski, and Cohen, 2008). In some developing countries, the burden of disease is said to have 'quadrupled' due to the HIV/AIDs epidemic, emerging diseases (especially as they relate to climate change), crime and poverty-driven environmental health outcomes such as diarrhoea. Furthermore, observations in developing countries have indicated that effects of air pollution on these nations may be greater because they are more vulnerable as a result of their nutritional status and lifestyle (Romieu and Hernandez-Avila, 2003).

In South Africa, the National Environmental Management: Air Quality Act (Act 39 of 2004) allowed for the development of priority areas for air quality management interventions to ensure compliance with national air quality management standards and to control potential harmful air pollution impacts on human health. To date, the Vaal Triangle Air-Shed Priority Area (DEAT, 2006) and the Highveld Priority Area (HPA) (DEAT, 2007) have been declared as priority areas (Figure 1). The main towns in the HPA are eMalahleni (previously Witbank) and Middelburg in the Mpumalanga province. The HPA is characterised by intense mining, coal-fired power plants, industries, including iron and steel manufacturing, chemical plants and agricultural activity. In addition to industrial sources, motor vehicles and domestic fuel burning also contribute to air pollution. Since these two sources emit pollutants at ground level, they may contribute more to human exposure than other sources.

To date, two studies have assessed the human health risks posed by air pollution potentially impacting upon communities living in the HPA. In 1990, the respiratory health of children living in the HPA was compared to that of children living further east in an environment deemed to have less air pollution (Zwi et al., 1991). The 'Highveld' children were found to be more likely to have a morning cough, wheeze, chest colds and asthma compared to the other group. Factors that were identified to increase the risk of children developing these symptoms included attendance of school in the exposed area, cigarette smoking, and not using electricity for cooking in the home. A smaller, cross-sectional study (involving 377 households) was also undertaken in 2006 in eMbalenhle, near Secunda (John et al., 2008). One of the aims of this study was to identify risk or vulnerability factors that may be significantly associated with respiratory health outcomes. The prevalence of health outcomes (including asthma, chronic asthma and pneumonia) were surprisingly low. Apart from these two studies, no further respiratory health studies have been performed thus far in the HPA. 
To fill this gap, and to build onto knowledge generated in the previous studies, a more comprehensive study was initiated to understand the potential impacts of environmental pollution, both air and water pollution, on communities in the HPA. This paper describes one part of this study pertaining to ambient air quality and addresses potential exposure to air pollution and airrelated human health among a low income community living in the HPA in order to better understand the impact of air pollution on human health.

\section{Methods}

\section{Study design}

This paper reports on air quality, personal exposure risk and air-related human health outcomes of a dual arm, cross-sectional study that also examined waterrelated health in a sample of households in a low income community in the HPA. Participating households answered a questionnaire about demographics, possible exposure to water and air pollutants, use of the local river, sanitation, solid waste removal, nutrition, energy use, health and healthcare, personal hygiene and socio-economic factors. A pilot study among 96 households was done prior to implementation of the full study. Ambient air quality monitoring was done at a safe location in the community measuring ambient levels of particulate matter, sulphur dioxide $\left(\mathrm{SO}_{2}\right)$, nitrogen dioxide $\left(\mathrm{NO}_{2}\right)$, lead $(\mathrm{Pb})$ and transition metals: mercury $(\mathrm{Hg})$ and manganese $(\mathrm{Mn})$. The first three pollutants are National Criteria Pollutants for which recent National Standards have been set under the Air Quality Act (Act No. 39 of 2004) (DEA, 2009). It was decided to include some transition metals in the analysis, since it is known that these metals may cause oxidative and inflammatory reactions in cells (Di Pietro et al., 2009). Mercury was included since it is emitted through the combustion of coal. There are coal-fired power plants, industries using coal, as well as domestic coal use in the area. Manganese was included, because methylcyclopentadienyl manganese tricarbonyl (MMT) is a fuel additive, while $\mathrm{Pb}$ is being phased out. There are also industries in the area emitting $\mathrm{Mn}$. This air quality monitoring coincided with the questionnaire survey. Ethical approval for this study was granted by the CSIR Research Ethics Committee (No 04/2010).

\section{Study area}

The study area constituted a geographical area of approximately $10 \mathrm{~km}^{2}$ and is referred to as the town of KwaGuqa (25 51' 46.23" S 29 07' 13.88" E) in the Mpumalanga Province (Figure 1). The HPA Baseline Assessment (DEA, 2010) showed that the area with the most air pollution in the HPA was the Witbank / Ferrobank area including the low-income communities of KwaGuqa. KwaGuqa town comprises informal dwellings and low cost housing. Some sections of the town are electrified, have water reticulation and water-borne sewerage, while other sections, especially newly inhabited sections, have no electricity or services (Balmer, 2007). Participating households were drawn from three suburbs within KwaGuqa town, namely, KwaGuqa Extension 5,
Vosman and Empumelelweni. KwaGuqa Extension 5 and Vosman are located alongside the Brugspruit (a small river), but represent two different socioeconomic groups, while Empumelelweni is located further away from the Brugspruit. The estimated population size by suburb was 2627 for KwaGuqa Extension 5; 3857 for Vosman (including Vosman and Vosman Extension 15, 16 and 17); and 7435 for Empumelelweni (including Empumelelweni A and B, and KwaGuqa Extensions 10 and 11).

\section{Participants and procedures}

A multi-stage probability sample was implemented. An equal number of household interviews was planned for each of the three suburbs ( $n=334)$. Street blocks were randomly selected and therein a random starting point was selected (i.e. North-east, North-west, South-east or South-west). A random starting house was selected choosing one of the first three houses using a random number list. From the starting house, the fieldworker walked around the block in a clockwise direction and interviewed every third house. When respondents refused to participate or were not present, the next house in the sequence was selected. Inclusion criteria stipulated that participants must be older than 18 years of age and not be under the influence of any substance at the discretion of the fieldworker.

Sixteen fieldworkers were recruited from the three study suburbs and attended a 6-day training period, with the last day used for piloting. A training manual used in similar studies was adapted and applied. Fieldworkers were familiarised with the questionnaire, protocol for administering the questionnaire and the electronic device used to ask the questions and record responses. Fieldwork was carried out by the fieldworkers using consistent principles from the protocol from 11 - 26 October 2010.

\section{Questionnaire}

The household questionnaire was derived from previously applied questionnaires (Terblanche et al., 1992; Richards et al., 1996). The questionnaire was transferred to mobile electronic devices beforehand for ease of data capture and data quality assurance. Each participant was read an information sheet about the study and asked to give written consent prior to administering of the household questionnaire. The questionnaire asked each respondent about demographics, possible exposure to water and air pollutants, use of the local stream, sanitation, solid waste removal, nutrition, energy use, health and healthcare, personal hygiene and socio-economic factors.

\section{Ambient $A Q$ monitoring}

Ambient air quality monitoring was done for one month at a safe location (community member's house) to monitor concentrations of particulate matter $\mathrm{SO}_{2}, \mathrm{NO}_{2}, \mathrm{~Pb}$ and the transitional metals $\mathrm{Hg}$ and $\mathrm{Mn}$. Particulate matter mass was monitored using a TOPAS (Turnkey Instruments SA) real-time airborne particulate matter monitor. The instrument 
can simultaneously monitor the mass concentrations of total suspended particulate matter (TSP), $\mathrm{PM}_{10}$ (particulate matter with a diameter equal to or smaller than $10 \mu \mathrm{m}$ ), $\mathrm{PM}_{2.5}$ (particulate matter with a diameter equal to or smaller than $2.5 \mu \mathrm{m}$ ) and $\mathrm{PM}_{1}$ (particulate matter with a diameter equal to or smaller than $1 \mu \mathrm{m}$ ), as well as local wind speed and local wind direction. The instrument has an internal data logger that records the mass concentration every second and averages the particle mass concentrations at 15minute intervals. A pump continuously draws an air sample (flow rate $=0.6 \mathrm{~L} / \mathrm{min}$ ) through the instrument, and the particle size and mass concentrations were measured using a light-scattering technique that analysed the individual particles as they passed through a laser beam. These same particles were then collected on a reference filter. After the first two weeks of monitoring, the filter was analysed for $\mathrm{Mn}$ (a neurotoxic compound) and $\mathrm{Pb}$ by atomic absorption spectroscopy. Monitoring then continued for another two weeks, after which the filter was again analysed for $\mathrm{Mn}$ and $\mathrm{Pb}$.

The gases $\mathrm{SO}_{2}$ and $\mathrm{NO}_{2}$ were sampled using Radiello passive samplers. Samplers were exposed for two weeks at a time. After exposure, samples were leached with water containing hydrogen peroxide according to the CSIR method SOP WI-FARAE-011, and the solution was analysed for sulphate, nitrite and nitrate anions by ion chromatography. Atmospheric $\mathrm{SO}_{2}$ and $\mathrm{NO}_{2}$ concentrations were calculated taking into account the exposure time, uptake rate as stipulated by Radiello, and ambient temperatures which were obtained for the station at Witbank Airport from the South African Weather Service. Mercury was also monitored for two weeks at a time using SKC Carulite $200 \mathrm{mg}$ tubes. The tubes were opened and connected to a vacuum pump operating at $0.2 \mathrm{~L} / \mathrm{min}$. The tube content was analysed for mercury by cold vapour atomic absorption spectroscopy. It should be noted that this method will only provide total atmospheric mercury values comprised of elemental, oxidised and particulate-bound mercury (Trüe et al., 2010).

\section{Quality control and data assurance}

Quality control and data assurance for the survey data was performed by means of follow-up interviews with participants. A random sample (15\%) of records was drawn from the full dataset to achieve a realised sample of $10 \%$ for telephonic follow-up interviews. Systematic sampling was performed by using a random record in the full dataset as the starting point and selecting every $7^{\text {th }}$ record thereafter. A shortened version of the original structured interview was repeated over the phone and 50 key variables were captured. This was done by a single evaluator fluent in multiple languages to ensure consistency. A total of 174 participants were telephoned. Of these, 127 answered, 121 completed the telephonic shortened version of the questionnaire (6 of those who answered the telephone call did not participate in the face-to-face interview). Only $10 \%$ of the follow-up records contained one deviation in the 50 fields checked, demonstrating sound intra- and inter-rater reliability. In cases where deviations from original responses were found during quality control, corrective action was taken to update records accordingly.

The air quality monitoring equipment was installed and maintained by the supplier according to standard protocols. The applicability of $\mathrm{SO}_{2}$ and $\mathrm{NO}_{2}$ analyses as sulphate and nitrate determination by ion chromatography was guaranteed by the use of independent reference materials (certified standards) as well as participation in the World Meteorological Organisation-Global Atmospheric Watch (WMO-GAW) inter-comparison scheme. Certified standards were also used during metal analyses.

\section{Data analysis}

Questionnaire data were imported into STATA and analysed to determine descriptive statistics. The primary unit of analysis was the household.

\section{Results and Discussion}

Community demographics, services and amenities The distribution of households selected for the survey by sub-area is indicated in Table 1. A total of 1639 household interviews were attempted by the 16 fieldworkers. From these, 1180 interviews were possible because in 375 instances no one was at home, 74 people refused to participate and 10 people did not feel safe to answer the questions. Following quality control and data assurance procedures, the final workable dataset comprised 1003 households (final response rate $=61.2 \%$ ) reflecting a total number of 4190 respondents.

The oldest person-age recorded was 98 years, with the average age being 26.3 years. There were slightly more males $(53 \%)$ than females in the study sample. About $16 \%$ of respondents had not completed any schooling while $5 \%$ indicated that they had a tertiary education. Individuals who were unemployed and looking for work constituted $20 \%$ of the sample, $19 \%$ had full-time paid employment and $31 \%$ were school pupils or full-time students.

The main source of water supply was piped water into the house $(70 \%)$, or a stand pipe or borehole in the yard (21\%). A communal pipe or borehole outside the yard was used by $4 \%$ of households. About $14 \%$ of those households which used a communal source of water indicated that it was used by more than 75 households. Where water was collected in containers (i.e. no piped water into the house) these were cleaned with detergent by $92 \%$ of households, with $80 \%$ of households having cleaned them during the past week. Just over $20 \%$ of all households indicated that they treated their water, mostly by boiling (66\%). A total of $72 \%$ of all households interviewed indicated that they were storing drinking water in their house. Of the $78 \%$ of households who indicated that they used a scoop to take water from the storage container, $77 \%$ indicated that they may drink from the scoop, too. 
Responses indicated that $97 \%$ of households had at least one toilet in the yard. Almost $70 \%$ of these toilets were a flushed-to-pipe sewer system. Refuse was collected from $63 \%$ of households, of which $82 \%$ had weekly-collection. Where refuse was collected, $85 \%$ of households paid for the removal service. If refuse was not collected, $63 \%$ of households indicated that refuse was mostly disposed of outside the yard, of which $91 \%$ disposed in a waste pit or dump site. Houses were mostly constructed of brick or blocks ( $80 \%$ of households), with $23 \%$ of households having 3 bedrooms, $45 \%$ having 2 bedrooms and $19 \%$ having 1 bedroom in the house. The majority of respondents $(76 \%)$ indicated that there were between 1 and 6 people living in the house on a dayto-day basis.

\section{Health and wellbeing}

Survey results suggested that approximately $77 \%$ of households perceived their health to be good. This corroborates the results of a previous study in which $90 \%$ of respondents considered the health of family members living in their household to be good (John et al., 2008). The reported prevalence of health outcomes was generally low. Sinus-reported symptoms were the most frequent $(42 \%$ of households had at least one case), followed by high blood pressure (36\% of households) and arthritis (18\% of households). Approximately $10 \%$ of households reported the presence of at least one case of asthma in their household. According to the South African Demographic Health Survey (SADHS, 1998), the prevalence of asthma in the South African adult (age $15+$ ) population was $7 \%$ for men and $9 \%$ for women at the time. A total of $17 \%$ of respondents indicated that a member of the household has been absent from work or studies because of an illness in the past month. Almost $23 \%$ of households indicated that at least one member had access to medical care through medical aid or through a clinic at work. Regarding transport and health facility accessibility, most households were close to a transport mode but not close to a hospital. About $90 \%(n=1217)$ of children (aged 15 years or less) had been immunised.

Almost $45 \%$ of households indicated that their members usually ate fruit and vegetables daily and most produce had been bought from a nearby shop. Protein such as fish and chicken were being consumed daily by $61 \%$ of households. Of the $65 \%$ of households with school-going children, $32 \%$ indicated that children got food at school regularly.

\section{Ambient air quality}

Figure 2 displays time series of the real-time 15minute average mass concentrations of $\mathrm{PM}_{10}, \mathrm{PM}_{2.5}$, and $\mathrm{PM}_{1}$ as well as the 15-minute average local wind speed measurements from 21 September to 19 October 2010 (spring months) measured at the community member's house in KwaGuqa. During this measurement period, the PM measurements were highly variable. The minimum and maximum values for $\mathrm{PM}_{10}, \mathrm{PM}_{2.5}$, and $\mathrm{PM}_{1}$ were all measured on the same days; the minimum values were recorded on 15
October 2010 in the morning and the maximum values were recorded on 10 October 2010 in the late morning/early afternoon. The $\mathrm{PM}_{10}$ concentrations ranged from $0.6 \mu \mathrm{g} / \mathrm{m}^{3}$ on 15 October 2010 to 490.3 $\mu \mathrm{g} / \mathrm{m}^{3}$ on 10 October 2010. The $\mathrm{PM}_{2.5}$ concentrations ranged from $0.19 \mu \mathrm{g} / \mathrm{m}^{3}$ on 15 October 2010 to $239.83 \mu \mathrm{g} / \mathrm{m}^{3}$ on 10 October 2010. The $\mathrm{PM}_{1}$ concentrations ranged from $0.06 \mu \mathrm{g} / \mathrm{m}^{3}$ on 15 October 2010 to $85.63 \mu \mathrm{g} / \mathrm{m}^{3}$ on 10 October 2010 . The local wind speed was also variable and on average peaked in the morning (6:00) and had a minimum value in the evening (19:00). Measured PM concentrations, however, did not show a strong dependence on local wind speed.

The average daily concentrations of monitored $\mathrm{PM}_{10}$, $\mathrm{PM}_{2.5}$, and $\mathrm{PM}_{1}$ mass concentrations are given in Figure 3. Under the South African Air Quality Act, only $\mathrm{PM}_{10}$ ambient concentrations are regulated, and not $\mathrm{PM}_{25}$ or $\mathrm{PM}_{1}$ mass concentrations. None of the $\mathrm{PM}_{10}$ daily averages exceeded the South African National 24-hour standard of $120 \mu \mathrm{g} / \mathrm{m}^{3}$ during the monitoring period, although the 15-minute averages were above $120 \mathrm{\mu g} / \mathrm{m}^{3}$ on several occasions (Figure 2). The average 24-hour $\mathrm{PM}_{10}$ concentration for the measurement period was $59.6 \mu \mathrm{g} / \mathrm{m}^{3}$ and maximum 24-hour $\mathrm{PM}_{10}$ concentration was $107 \mu \mathrm{g} / \mathrm{m}^{3}$ on 30 September 2010, which is slightly lower than the national 24-hour standard.

The diurnal variation of the normalized $\mathrm{PM}_{10}$ mass concentration measurements is shown in Figure 4. To normalize the $\mathrm{PM}_{10}$ values, each 15-minute average point was divided by its respective daily average. Thus, a value of 1 in Figure 4 indicates the daily average. The $\mathrm{PM}_{10}$ mass concentration during this campaign peaked at midday (12:00-13:00), but also had smaller peaks in the early morning (1:00-2:00) and evening (17:00). The minimum occurred in the late evening (22:00). The diurnal variation for the duration of the study, suggests that during this time period, local sources of $\mathrm{PM}_{10}$ contributed throughout the day. Since there is no build-up of pollution in the evening and decrease in the day, the $\mathrm{PM}_{10}$ mass concentration for this month of measurements was not dictated by daytime convective mixing followed by the formation of a night time boundary layer.

A pollution rose (Figure 5) compiled from the monitored 15-minute averaged $P_{10}$ mass concentrations and wind direction data shows that measured $\mathrm{PM}_{10}$ mass concentrations up to $200 \mu \mathrm{g} / \mathrm{m}^{3}$ were seen at all local wind directions. The highest levels $\left(>200 \mu \mathrm{g} / \mathrm{m}^{3}\right)$ were generally, though not exclusively, seen when the wind came from the northwest and north-east. In addition, no strongly evident relationship was seen between local wind speed and $\mathrm{PM}_{10}$ mass concentrations (not shown); however with high local wind speeds $\left(u \geq 3 \mathrm{~m} / \mathrm{s}\right.$ ) the $P_{10}$ mass concentrations measured were all below $200 \mu \mathrm{g} / \mathrm{m}^{3}$. This lack of a strong correlation with local wind speed and wind direction, together with the highly variable particulate mass concentrations, suggests a variety 
of sources of PM throughout the area.

Results of the passive samplers $\left(\mathrm{SO}_{2}\right.$ and $\left.\mathrm{NO}_{2}\right)$ are given in Table 2. The averages of the two-week $\mathrm{SO}_{2}$ and $\mathrm{NO}_{2}$ concentrations analysed were relatively low. The maximum concentration for $\mathrm{SO}_{2}$ and $\mathrm{NO}_{2}$ were 10 $\mu \mathrm{g} / \mathrm{m}^{3}$ and $22 \mu \mathrm{g} / \mathrm{m}^{3}$, respectively. No two-weekly or monthly standards for $\mathrm{SO}_{2}$ or $\mathrm{NO}_{2}$ exist. However, should these maximum concentrations prevail, the annual standards of $50 \mu \mathrm{g} / \mathrm{m}^{3}$ and $40 \mu \mathrm{g} / \mathrm{m}^{3}$ for $\mathrm{SO}_{2}$ and $\mathrm{NO}_{2}$, respectively, are unlikely to be exceeded.

Analysis of the $\mathrm{PM}_{10}$ filter after the first two weeks of exposure showed a concentration of $14.7 \mu \mathrm{g} / \mathrm{m}^{3}$ of $\mathrm{Mn}$ while $\mathrm{Pb}$ concentrations were below the detection limit of $0.01 \mu \mathrm{g} / \mathrm{m}^{3}$. Analysis of the second filter (after the second two-week period) showed that both Mn and $\mathrm{Pb}$ concentrations were below the detection limit of $0.01 \mathrm{\mu g} / \mathrm{m}^{3}$. It is possible that the difference in these results could have been caused by changes in predominant wind direction between the two-week periods. There is no South African National standard for $\mathrm{Mn}$ in ambient air, while an annual standard of 0.5 $\mu \mathrm{g} / \mathrm{m}^{3}$ exists for $\mathrm{Pb}$. In the absence of a National standard for $\mathrm{Mn}$, the WHO guideline of $0.15 \mu \mathrm{g} / \mathrm{m}^{3}$ may be used (WHO, 1999). This guideline was based on a no observed effect level (NOEL) (for neurological effects in workers) of $30 \mu \mathrm{g} / \mathrm{m}^{3}$. However, this guideline is for an annual average and the monitoring period for this study was one month

Total $\mathrm{Hg}$ concentrations were $2.0 \mathrm{ng} / \mathrm{m}^{3}$ during the first two-week period and $2.4 \mathrm{ng} / \mathrm{m}^{3}$ during the second two-week period. The main source of $\mathrm{Hg}$ in the area is likely to be coal burning. These concentrations correlate with results of a study by Trüe et al. (2010) where $\mathrm{Hg}$ was monitored on a weekly basis between 29 October 2009 and 3 December 2009 in eMalahleni town; the average $\mathrm{Hg}$ concentration for that monitoring period was found to be $1.8 \mathrm{ng} / \mathrm{m}^{3}$. South Africa does not have a National standard for $\mathrm{Hg}$. The WHO guideline (WHO, 1999) for inorganic mercury in air is $1000 \mathrm{ng} / \mathrm{m}^{3}\left(1 \mu \mathrm{g} / \mathrm{m}^{3}\right)$, which is an annual guideline based on a lowest observed adverse effect level (LOAEL) of $20 \mu \mathrm{g} / \mathrm{m}^{3}$ due to renal effects in humans. This guideline was not exceeded in this study or in the study by Trüe et al. (2010).

In terms of indoor air pollution exposure, tobacco smoking was prevalent in $24 \%$ of households. Coal was used for cooking and heating in $6 \%$ and $29 \%$ of households, respectively. In a study by Balmer (2007) coal used in this area was found to be of a low quality. The 'Basa njengo Magogo' or top-down method of lighting a fire was used at $13 \%$ of households. Electricity was mostly used for cooking (75\%) and heating (52\%).

\section{Conclusions}

From the relatively limited ambient air monitoring campaign measuring $\mathrm{PM} \mathrm{SO}_{2}, \mathrm{NO}_{2}, \mathrm{Hg}, \mathrm{Pb}$ and $\mathrm{Mn}$ in the study area, preliminary evidence suggests that ambient air quality during September - October 2010 was highly variable with a variety of local sources. In addition, the ambient air quality was not in excess of National standards. This may be because these months fall within spring when temperature inversions are less common and ambient temperatures are milder than during winter months, hence less coal is burnt for household heating. In Josipovic et al. (2009), $\mathrm{SO}_{2}$ and $\mathrm{NO}_{2}$ were monitored by passive sampling at 37 different sites over the HPA to determine the spatial distribution of these gases and their seasonality. Monitoring sites were situated mostly in rural areas away from urban centres, industrial point sources, main roads or other influences of air pollution. They found the highest concentrations directly over the Mpumalanga industrial Highveld. In the same study, a seasonal trend was more obvious for $\mathrm{SO}_{2}$ than for $\mathrm{NO}_{2}$, although $\mathrm{NO}_{2}$ was slightly elevated in summer. The concentrations of $\mathrm{SO}_{2}$ were higher in winter (Josipovic et al., 2009). The higher concentrations of $\mathrm{SO}_{2}$ in winter were most probably as a result of an increase in domestic coal use for heating during the cold winter months. Lourens et al. (2011) also studied the spatial and temporal distributions of gaseous air pollutants, including $\mathrm{SO}_{2}$ and $\mathrm{NO}_{2}$ in the HPA over the course of one year. The highest concentrations for $\mathrm{SO}_{2}$ and $\mathrm{NO}_{2}$, measured at any of the eight stations, were at eMalahleni (Witbank) especially during winter months. Annual averages were, however, below the National Standards.

Descriptive community demographic and health status statistics suggested that household members tended to be relatively young (i.e. average $=26$ years of age) and perceived themselves to be in good health. Some individuals did suffer from sinusitis and asthma; however, further statistical analyses will determine risk factors associated with these health outcomes. Together with a better understanding of local issues, which includes stakeholder concerns and community inputs, these results will improve understanding of risks in the community and provide useful information for improved decision- making.

\section{Acknowledgements}

This project was supported by a CSIR Parliamentary Grant. The communities, clinics and local councillors are thanked for their support and cooperation. The NOVA Institute are acknowledged for developing the survey plan and carrying out the fieldwork in collaboration with the CSIR.

\section{References}

Balmer, M. 2007. Household coal use in an urban township in South Africa. Journal of Energy in Southern Africa. 18 (3):27- 32

DEA, 2009. National Environmental Management: Air Quality Act (39/2004), Government Gazette. No. 32816, Government Notice No. 1210:6-9.

DEA, 2010. State of Air 2005. A Report on the State of the Air in South Africa. Department of Environmental Affairs, Pretoria. 
DEAT, 2006. Declaration of the Vaal Triangle Air-shed Priority Area in terms of Section 18(1) of the National Environmental Management: Air Quality Act 2004 (Act No. 39 of 2004). Government Gazette No. 28732, Government Notice No. 365:6-7.

DEAT, 2007. Declaration of the Highveld as a Priority Area in terms of Section 18(1) of the National Environmental Management: Air Quality Act (No. 39 of 2004). Government Gazette No. 30518, Government Notice No. 1123:3-4.

Di Pietro A, Visalli G, Munaò F, Baluce B, La Maestra S, Primerano P, Corigliano F, and De Flora S. 2009. Oxidative damage in human epithelial alveolar cells exposed in vitro to oil fly ash transition metals. International Journal of Hygiene and Environmental Health. 212:196-208.

John, J, Matooane, M, Oosthuizen, MA, and Wright, C. 2008. Vulnerability to air pollution: to intervene or not to intervene. $2^{\text {nd }}$ CSIR Biennial Conference. Pretoria, 17-18 November 2008. Available at http://researchspace.csir.co.za/dspace/bitstream/1 0204/2558/1/John_2008.pdf.

Josipovic, M, Annegarn, HJ, Kneen, MA, Pienaar, JJ and Piketh, SJ. 2009. Concentrations, distributions and critical level exceedance assessment of $\mathrm{SO}_{2}$, $\mathrm{NO}_{2}$ and $\mathrm{O}_{3}$ in South Africa. Environmental Monitoring Assessment. DOI 10.1007/s10661-009-1270-5.

Krzyzanowski, M and Cohen, A. 2008. Update of WHO air quality guidelines. Air Quality Atmosphere and Health. 1:7-13.

Lourens, AS, Beukes, JP, Van Zyl, PG, Fourie, GD, Burger, JW, Pienaar, JJ, Read, CE and Jordaan JH. 2011. Spatial and temporal assessment of gaseous pollutants in the Highveld of South Africa. South African Journal of Science. 107(1/2):55-62.

Richards, GA, Terblanche, AP, Theron, AJ, Opperman, L, Crowther, G, Myer, MS. 1996. Health effects of passive smoking in adolescent children. South African Medical Journal. 86:143-147.

Romieu, I. and Hernandez-Avila, M. 2003. Air Pollution and Health in Developing Countries: A Review of Epidemiological Evidence. (In McGranahan, G. and Murray, F. (eds). Air pollution \& Health in Rapidly Developing Countries). Earthscan, London. ISBN 185383985: 49, 58.

SADHS. 1998. South African Demographic and Health Survey - 1998. Department of Health, Pretoria, South Africa. [Online] Available: http://www.doh.gov.za/facts/sadhs-f.html (accessed 30 March 2011).

Terblanche, AP. Opperman, L, Nel, CM, Reinach, SG, Tosen, G and Cadman. 1992. Preliminary results of exposure measurements and health effects of the Vaal Triangle Air Pollution Health Study. South
African Medical Journal. 81:550-556.

Trüe, A, Forbes, P, Panichev, N and Okonkwo, J. 2010. The use of Sorbent Tubes and a Semicontinuous Emissions Monitor for the Determination of Atmospheric Total Gaseous Mercury in Pretoria, South Africa. Fresenious Environmental Bulletin. 19(12a):3007-3012.

WHO, 1999. WHO guidelines for air quality. [Online] Available: http://www.who.int/peh/air/ Airqualitygd.htm (accessed 30 March 2011).

WHO, 2007. Chronic Respiratory Diseases. [Online] Available: http://www.who.int/respiratory/en/ (accessed 30 March 2011).

WHO, 2010. World Health Statistics 2010. [Online] Available: http://www.who.int/mediacentre /factsheets/fs290/en/index.html (accessed 30 March 2011).

Zwi, S., Goldman, H.I., Kallenbach, J.M., Davies, J.C.A., Becklake, M.R. and Reinach, S.G. 1991. Respiratory Health Status of Children in the Eastern Transvaal Highveld. The Clean Air Journal. 8(3):1121.

List of Figures and Tables on the next page. 


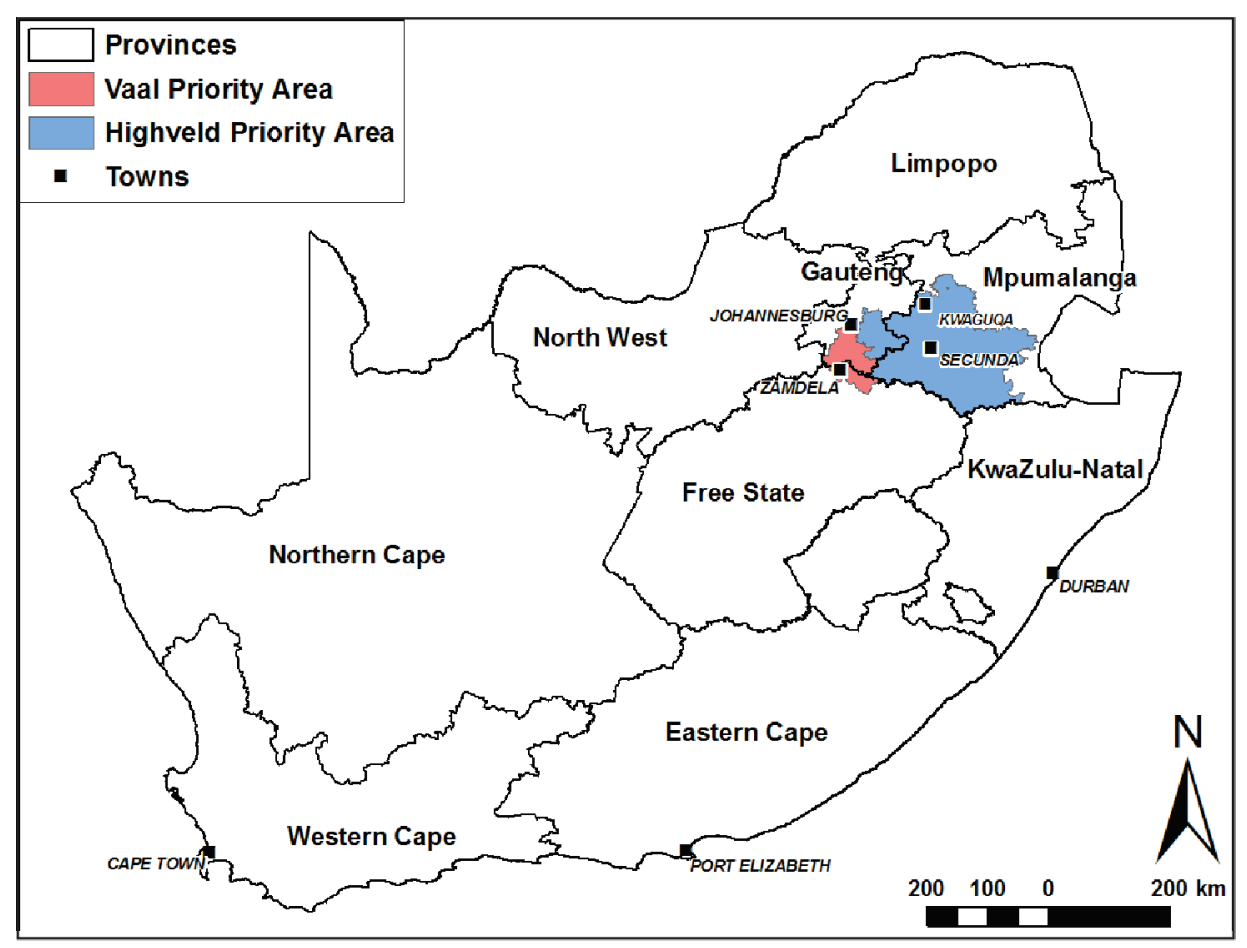

Figure 1. Detailed boundaries of the Highveld Priority Area (HPA) in blue and the Vaal Triangle Priority Area in red. KwaGuqa is located in the north-west of Mpumalanga Province.

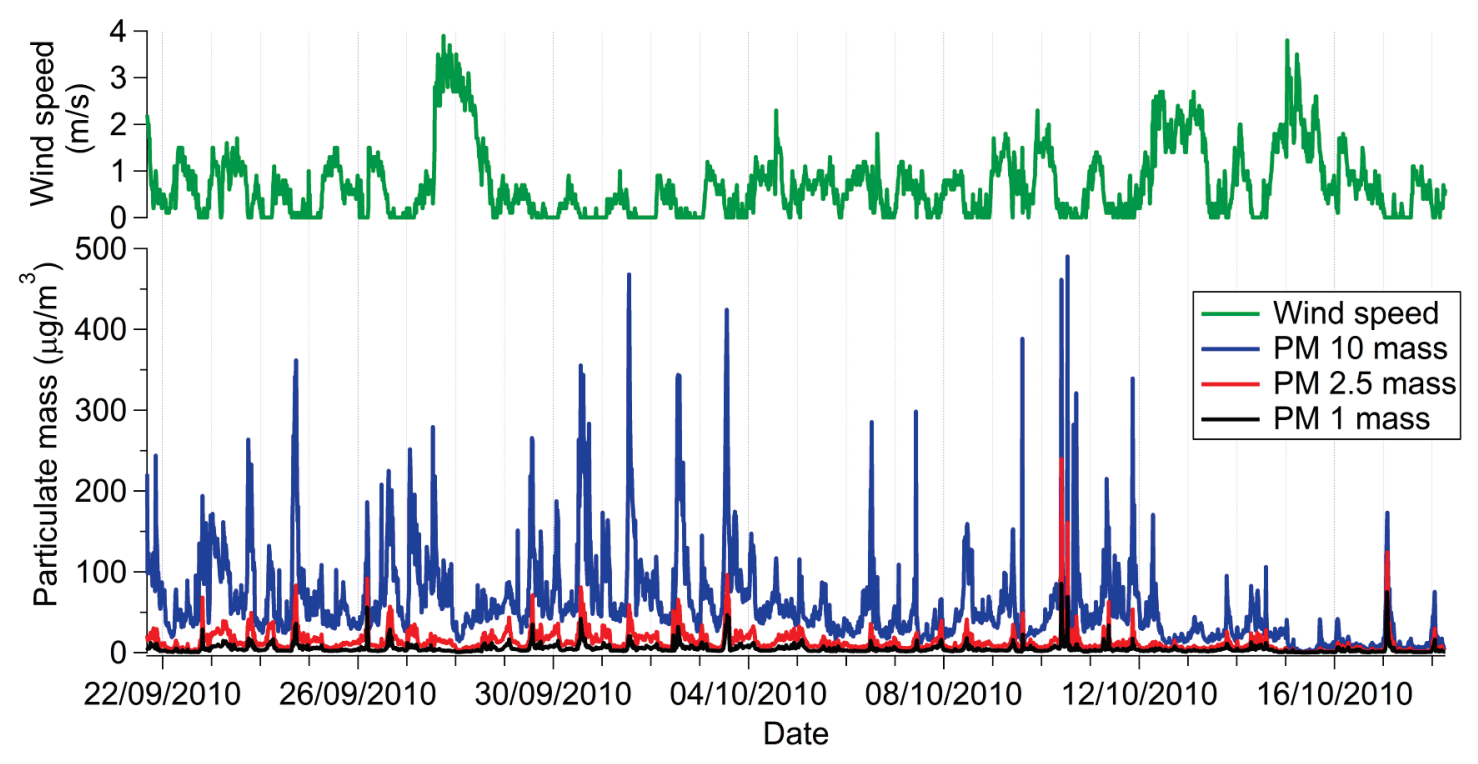

Figure 2. Time series of 15 -minute average $\mathrm{PM}_{10}, \mathrm{PM}_{2.5}$, and $\mathrm{PM}_{1}$ mass concentrations $\left(\mu \mathrm{g} / \mathrm{m}^{3}\right)$ and local wind speed monitored at the community member's house in KwaGuqa. 


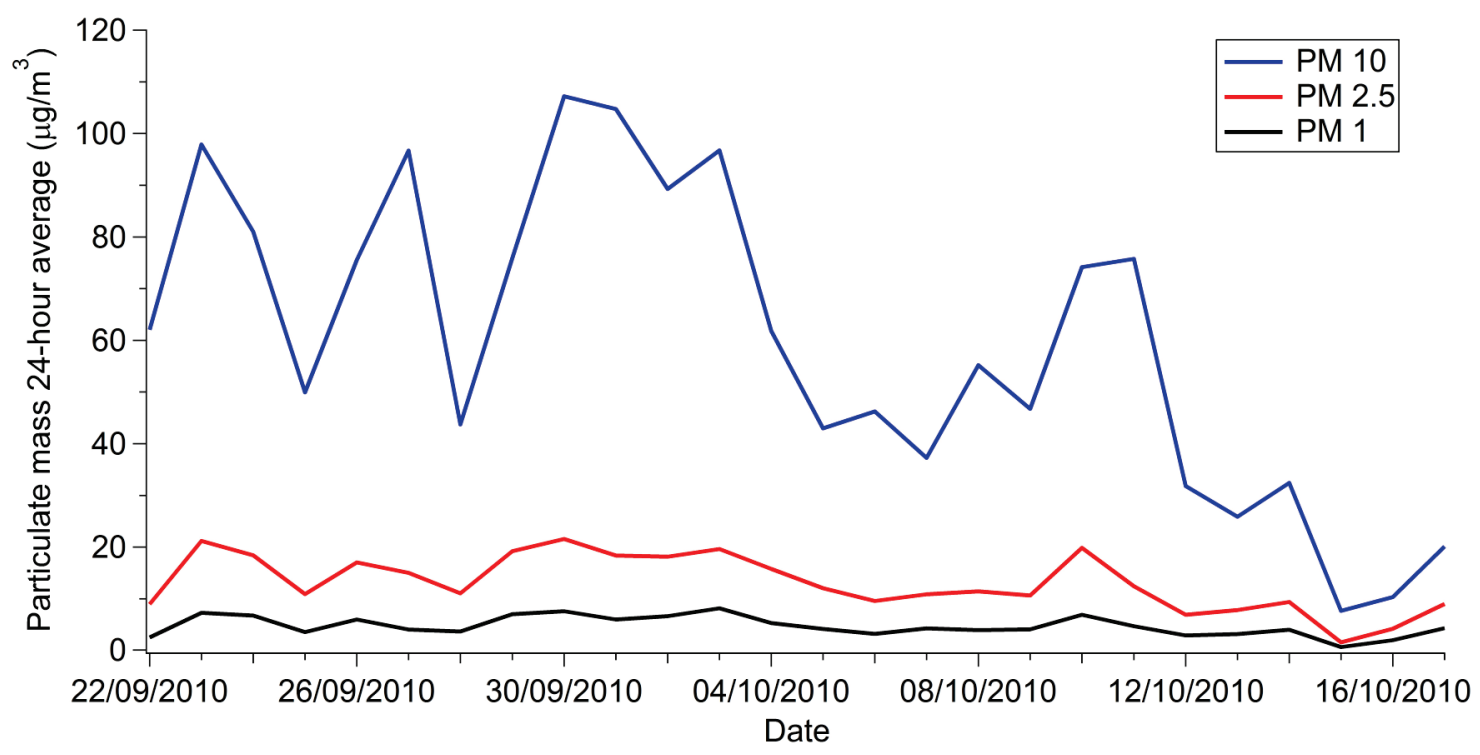

Figure 3. Time series of daily 24-hour average $\mathrm{PM}_{10}, \mathrm{PM}_{2.5}$, and $\mathrm{PM}_{1}$ mass concentrations $\left(\mu \mathrm{g} / \mathrm{m}^{3}\right)$ in KwaGuqa. The 24-hour South African National Ambient Air Quality Sta ndard for $\mathrm{PM}_{10}$ is $120 \mathrm{\mu g} / \mathrm{m}^{3}$.

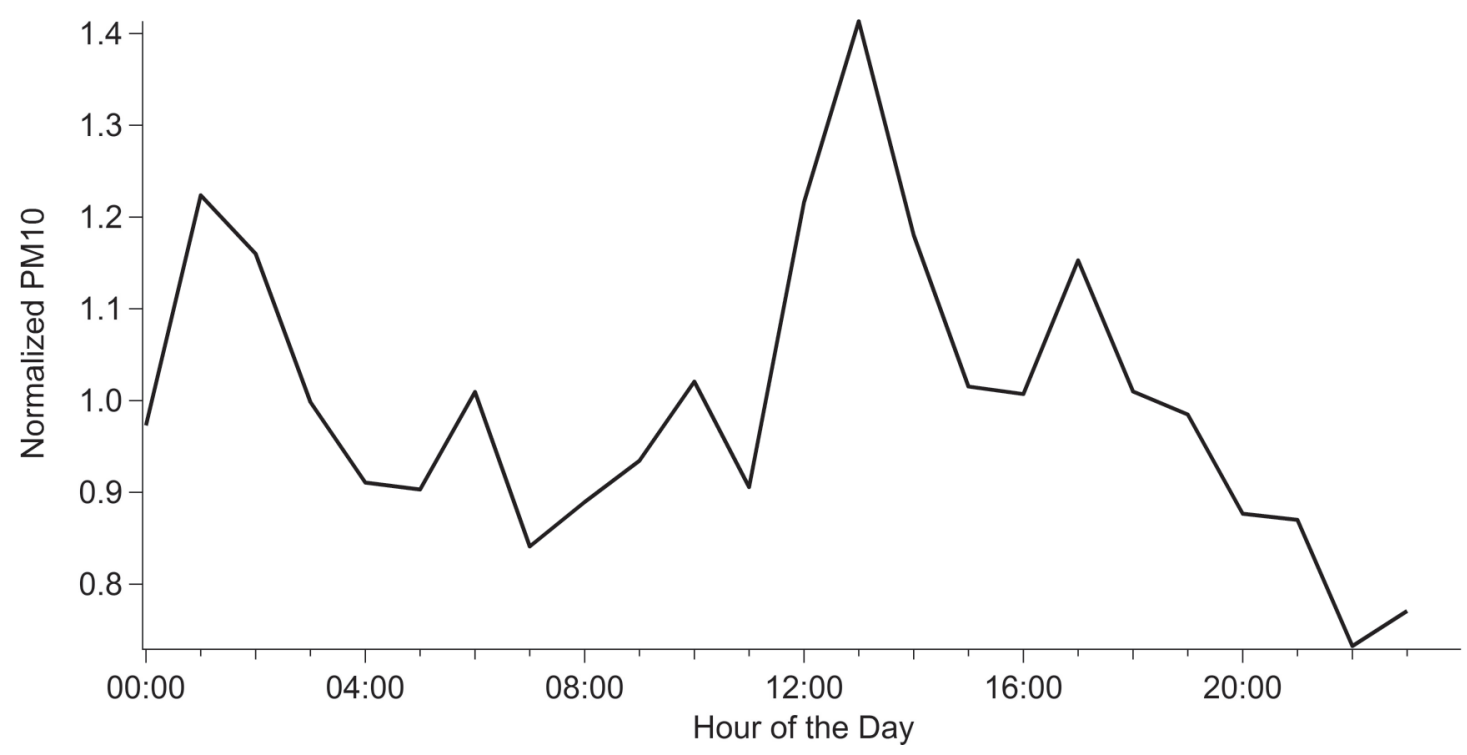

Figure 4. Diurnal variation of normalized $\mathrm{PM}_{10}$ mass concentrations. 


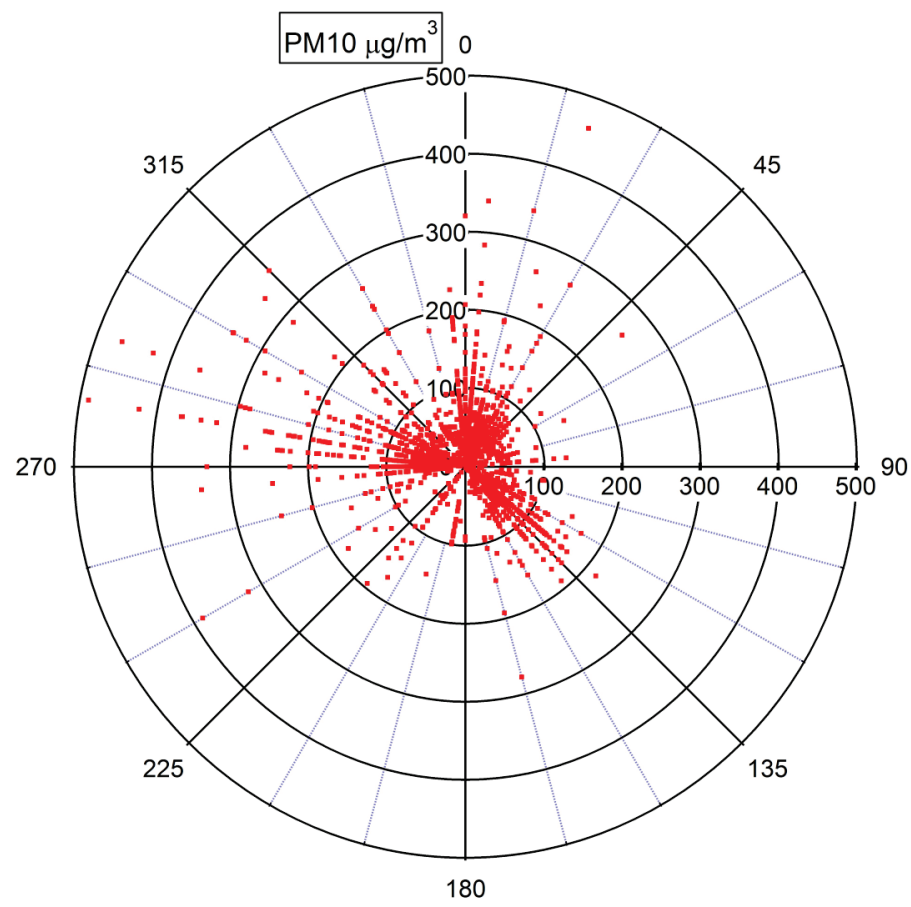

Figure 5. Pollution rose showing local wind direction versus the 15-minute averaged $\mathrm{PM}_{10}$ mass concentrations for 21 September to 19 October 2010 in KwaGuqa.

Table 1: Distribution of households in the different sub -areas.

\begin{tabular}{|l|c|c|}
\hline Suburb & $\begin{array}{c}\text { Number of households } \\
\text { (n) }\end{array}$ & $\begin{array}{c}\text { Percentage of total households } \\
\text { surveyed (\%) }\end{array}$ \\
\hline Vosman & 353 & 35 \\
\hline KwaGuqa Ext 4 & 186 & 19 \\
\hline KwaGuqa Ext 5 & 140 & 14 \\
\hline Empumelelweni & 324 & 32 \\
\hline Total & 1003 & 100 \\
\hline
\end{tabular}

Table 2. Results of passive $\mathrm{SO}_{2}$ and $\mathrm{NO}_{2}$ monitoring (two-week averages).

\begin{tabular}{|l|c|c|}
\hline Exposure duration & $\begin{array}{c}\mathrm{SO}_{2} \text { concentration } \\
\left(\boldsymbol{\mu g} / \mathbf{m}^{3}\right)\end{array}$ & $\begin{array}{c}\mathrm{NO}_{2} \text { concentration } \\
\left(\boldsymbol{\mu g} / \mathbf{m}^{3}\right)\end{array}$ \\
\hline 21 Sep - 5 Oct 2010 & 10 & 22 \\
\hline 5 Oct -19 Oct 2010 & 6.6 & 17 \\
\hline
\end{tabular}

